\title{
Financing Universal Health Coverage: A Systematic Review
}

\author{
Md. Jahir Uddin Palas \\ Department of Banking and Insurance, University of Dhaka \\ Email: jahir@du.ac.bd \\ Mahfuz Ashraf \\ School of Public Health and Community Medicine, University of New South Wales \\ Pradeep Kumar Ray \\ Centre for Entrepreneurship, Joint Institute- University of Michigan-Shanghai Jiao Tong University (SJTU), China \\ School of Public Health and Community Medicine, University of New South Wales
}

\begin{abstract}
Across the globe, a significant portion of the population lacks the essential healthcare services due to the rising cost of such services. To ensure healthcare for all, the idea of universal health coverage has evolved but affordability and equity of health services have become the major concerns in this regard. This paper presents a systematic review that offers a detailed picture of diverse issues of universal healthcare financing. Eight popular databases were thoroughly searched with appropriate keywords for finding relevant articles published within 1980 to 2016. After four constructive iterations with logical constraints, 24 articles were finally selected for finding significant research themes in universal healthcare finance arena. The characteristics of the studies were presented graphically from different aspects such as fields of publication, research approaches, geographic distribution etc. The themes, so found in the review, have been categorized into four broad themes with respective sub-themes. The broad themes were namely A) financing options for healthcare B) medical expenses C) inequality in healthcare finance, and D) development of healthcare finance. This systematic review analyzed the studies, discussed avenues, and concluded with gaps for future research in universal healthcare finance. The synthesis of multifarious concepts in the prevalent literature on financing universal healthcare offered profound insights of universal healthcare arena.
\end{abstract}

Keywords: Universal Health Coverage, Financing Healthcare, Systematic Review, Health Service Costs, Financial Policy Design for Healthcare

\section{Introduction}

Declaration of health as a fundamental human right in World Health Organization's (WHO) constitution of 1948 and the agenda of Health for All by Alma-Ata declaration of 1978 were instrumental behind universal health coverage. Equity in healthcare has been marked as the prime element in marking healthcare progress within different groups of a nation and across the national population [1]; [2]. While tracking the progress of universal healthcare coverage, World Health Organization (WHO) conducted a survey in 37 countries and published a report within the time frame of 2002 and 2012 which has been the first of its kind. According to the report published by World Bank and WHO, about 400 million people do not have access to essential health services around the globe [3]. From clean water to pregnancy care, these people lack proper access to one out of seven important health services, in the least severe case [3]. Although the number of people getting into the healthcare coverage is increasing, the coverage gap is also ever enhancing among world population [4]; [5].

The incidence of catastrophic health spending has been quite alarming as about 2 percent of the surveyed population experienced such catastrophic expenditure, which exceeded the $25 \%$ of their household expenditures [3]. Due to unaffordable healthcare costs, a significant portion $(6 \%)$ of the population has fallen below the extreme poverty line ( $\$ 1.25$ per day) and the percentage 
becomes an overwhelming $17 \%$ if the poverty measure is counted at $\$ 2$ per day [3].

Let alone poorer countries, developing nations have also been confronted with healthcare challenges for their citizens [6]; [7]. Ensuring adequate vaccination tops the list as, in 2009, about 24 million children lacked access to the basic lifesaving vaccines in poorest countries [8]. Among the disadvantageous children under the age of 5 years, more than 13 million has to accept unexpected death every year due to illnesses which could be treated or avoided with basic healthcare [8]. Only basic vaccination could save lives of such ill-fated children by $45 \%$, eliminating deaths because of infectious diseases. In addition, insufficient healthcare staff and health service equipment create barriers in offering healthcare service for all. Nations of Southeast Asia and Sub-Saharan Africa has approximately 6 times fewer doctors ( 1 for over 2000 citizens) than the standard set by developed countries [8]. To be exact, the materialization of universal health coverage requires people having access to health services without suffering in paying for such services [9]; [10]. A number of elements must be ensured for successful adoption of universal health coverage in any nation. A robust and efficient health system is the number one criteria, which include adequate promotion of health, proper preventive measures, early detection of health conditions, capacity for treating diseases and rehabilitation assistance [11]. Affordability criteria come second along with the availability of essential technologies for proper diagnosis and medicine for treating medical issues [11]. Sufficient self-motivated and well-trained health workers are also a prerequisite for universal health coverage. Last but not the least, an allaround combination of effective roles by other sectors, i.e. education, transport, and urban planning, is required for successful utilization of universal health coverage.

It is evident that universal health coverage exerts a positive impact towards the citizens' health directly [12]; [13]. The extent of productivity and active contribution from people increase much as long as good health is ensured [14]; [15]; [16]. Education experiences a giant leap as child mortality is reduced and people are saved from being fallen down the poverty line due to catastrophic health expenditure [17]; [18]; [19]; [20]. Therefore, to enforce sustainable development and improved wellbeing of people, universal health coverage has no other equal alternatives.

Universal healthcare coverage can be attributed to a situation where all of the residents of any geographical location are privileged with access to healthcare. Equity and affordability are considered as two of the prime considerations of universal healthcare [11] where equity means "the absence of systematic disparities in health (or in the major social determinants of health) between groups with different levels of underlying social advantage/disadvantage" [21]. The core ideas of health services in universal healthcare are based on the principles of healthcare practiced in countries with socialism [22].

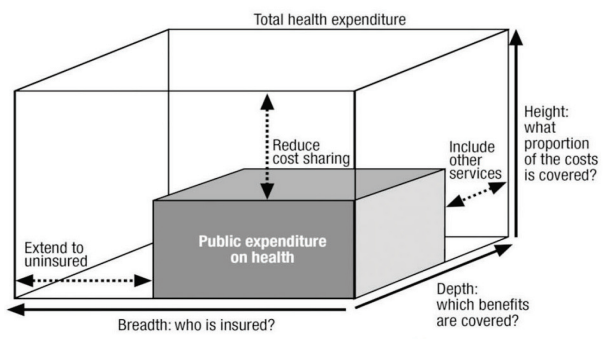

Fig. 1: Three Dimensions of Universal Health Coverage (Source: [23])

As per WHO [11], universal health care ensures that whole population would have affordable access to sufficient quality and effective healthcare services where better health promotions, illness prevention, treatments, palliative care, and rehabilitation will be included. The coverage cube as mentioned in figure 01 highlights the three core dimensions of universal health care, namely effective health services, population, and finance. It is quite likely that the realization of universal healthcare would be one of the basic elements of Sustainable Development Goals by United Nations (UN).

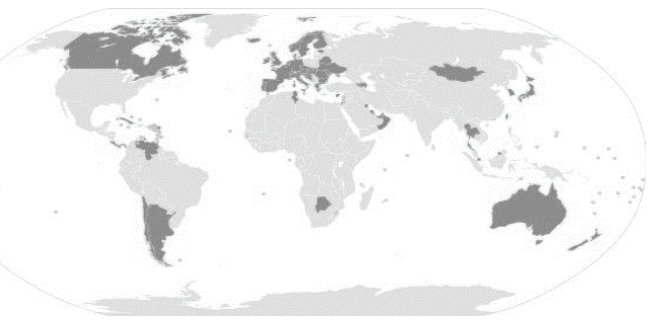

Fig. 2: Countries (in darker shade) with Universal Health Coverage (Source: [24])

The topmost challenge for enabling universal health coverage is the financial arrangement as healthcare services are expensive around the globe. Figure 03 presents a picture of health expenditure per capita in the OECD countries and the composition of government finance and private funding in such health expenses. 


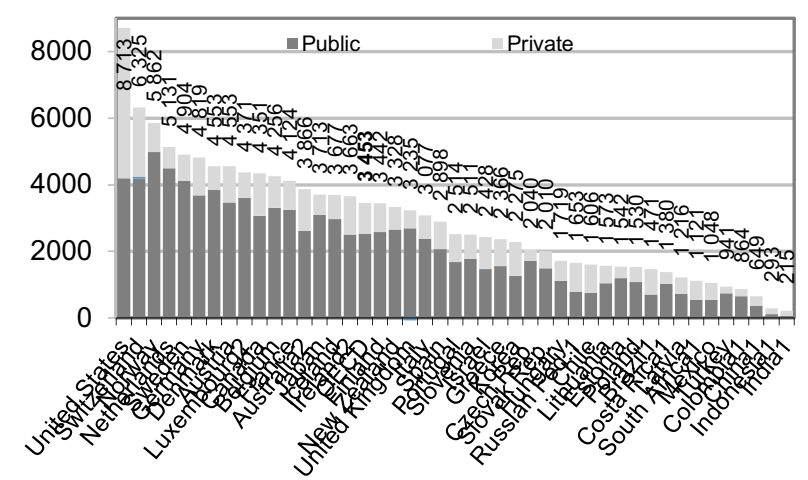

Fig. 3: Health expenditure per capita with public and private funding composition (in USD) (Source: [25])

As far as the out of pocket costs of people in healthcare is concerned, a substantial gap is prevalent between the poor and rich nations even after adjusting the government financing on healthcare. Surprisingly enough, citizens of low and middle-income nations spend much higher in healthcare as out of pocket costs [3]. Figure 04 shows the out of pocket costs in different countries of the world as a percentage of total expenditure in healthcare. The Southeast Asian countries can be quoted in this regard as more than $50 \%$ of the total health costs are paid in the form of out of pocket costs on an average in these countries. Citizens of 40 countries, mostly developed, in the below-mentioned map have to bear less than $15 \%$ of the total costs as out of pocket expenditure while in some other 48 countries, such percentage stays at $45 \%$ at a minimum.

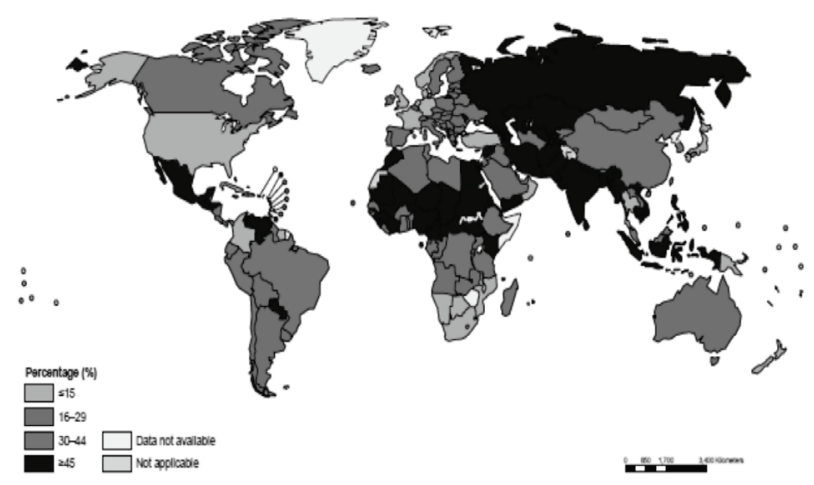

Fig. 4: Out of pocket expenditure (as \% of total healthcare cost) (Source: [3])
The public funding has been the primer in finance health services for many countries around the world, especially the OECD nations. However, increasing costs of healthcare services and funding demands of other crucial government sectors, i.e. education, infrastructure, food etc. call for an effective solution for universal healthcare financing. Figure 05 shows the expenditure on healthcare as a percentage of GDP for the OECD countries from 1980 to 2013. An increasing trend is evident in the graph which denotes rising costs of expenditure in healthcare. Among all the countries, healthcare spending is the highest in the USA (17.1\%) which is about $6 \%$ more than France $(11.6 \%)$, the second in the list [25].

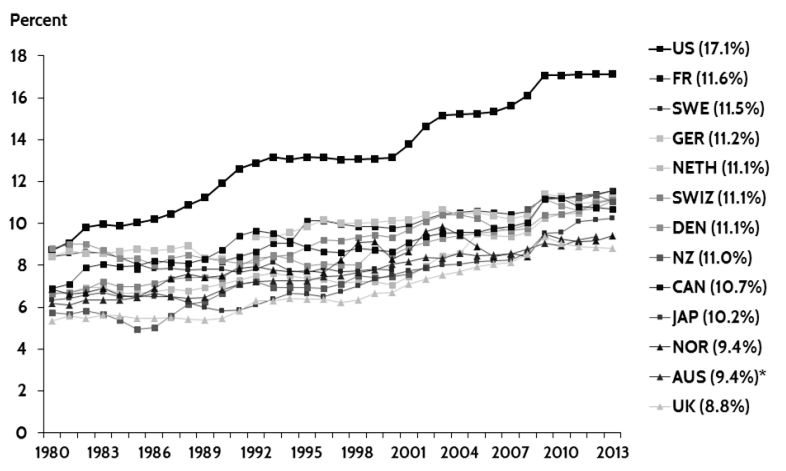

Fig. 5: Spending in healthcare (as \% of GDP) (Source: [25])

Because of high healthcare costs, the poorer section of the society will be untreated of diseases if people need to pay the costs of healthcare by their own [26]. Even the richer people will also face hardships in financing severe diseases and long-term sickness [27]; [28]. Thus, financial risk protection by pooling funds from different sources, i.e. tax, insurance contributions, government revenue etc., and spreading the burden of financing illness across the population is necessary. In this way, crosssubsidization between poor and rich is enabled while financing healthcare and efficient access to healthcare for all is ensured as healthy ones back up the sick ones [29]; [30]; [31]. A robust framework for financing universal healthcare has become the challenge for materializing the key objective of universal health coverage.

As the objectives of universal health coverage are preconditions to ensure a healthy nation and aligned with the enhanced wellbeing of citizens, authors of public health fields, along with other branches of healthcare, have found substantial interest in contributing to the literature of financing universal healthcare. However, 
studies in the universal health coverage financing arena need proper documentation in a thematic fashion. In addition, identifying the studies relevant to the financing of universal health coverage and a systematic synthesis of the key concepts in this avenue are still sporadic as publications in this field are increasing in recent times. Therefore, to offer the different stakeholders of universal health coverage a structured documentation on themes from existing publications, this article aims at providing a systematic literature review of universal health coverage from the lens of financial aspects.

\section{Method}

The major objective of this systematic review is to perform a review of the existing knowledge base for informing researchers and healthcare professionals about the multiple sorts of research patterns and the gaps in the concurrent literature of universal healthcare financing. For enabling a rigorous review process, the guidelines by Kitchenham [32] have been followed throughout the paper, which involves four consecutive steps: (1) Resource identification, (2) Selection of studies, (3) Data extraction and synthesis and (4) Data analysis.

\subsection{Resource identification}

In the initial step, Dieste, Grimán and Juristo [33] have suggested identifying the relevant keywords for searching articles in the experimental method. As per Vichitvanichphong, Kerr, Talaei-Khoei and Ghapanchi [34], a survey of relevant articles has been conducted in Google Scholar. From the first 410 search results, the keywords "Finance", "Public Private Partnership", "Sustainable Development Goals" were used with "Universal Health coverage" to cater the similar purpose of this study and thus, such keywords were found relevant. Therefore, the following search phrases were used in searching databases and the search settings, wherever possible, were set as the article should contain the phrase "universal health coverage" along with any of the "finance", "public private partnership", "sustainable development goals" in any of the article's titles, keywords, abstract and/or full text.

- ("universal health coverage OR universal healthcare OR UHC") AND

- ("cost” OR “costing” OR "finance" OR "financing") AND

- ("public private partnership" OR "PPP" OR "sustainable development goals" OR "SDG" OR "strengthening health systems")
To find the relevant studies, 8 databases were selected and the above-mentioned search phrases were used in them with appropriate search settings. The databases were IEEE, Emerald, Taylor and Francis, ScienceDirect, JSTOR, Wiley online library, PubMed and Google Scholar. The studies published between 1980 and 2016 (May) were considered for the review. Among the keywords, "universal health coverage" (and/or) "finance" yielded the most relevant studies from the selected databases.

\subsection{Selection of studies}

Relevant papers were filtered from the initial search results. At the preliminary level, searches were conducted on the databases with the keywords and results returned with 68132 articles. In the first iteration, irrelevant articles were excluded based on certain criteria as listed below:

- did not focus on universal health care

- were not peer reviewed

- were not available online

- were not in the English language

- did not focus on healthcare financing

Such exclusion criteria resulted in 172 articles with which the second stage of iterations was conducted. Following additional criteria were included in the second stage for inclusion of each of the articles:

- should be in the relevant field of healthcare finance

- should have empirical evidence of finance or costing of healthcare

- $\quad$ should have findings applicable to relevant fields

- $\quad$ should have globally generalizable outcomes

45 papers have been sorted out after the second stage of iteration among which two articles were found to be duplicate. The third iteration has looked into the citation matters and searching papers that cited the articles found in first and second stages of iteration. With additional criteria, 24 articles were selected in the final stage of iteration. Due to the specialized nature of this systematic review on financing issues of universal healthcare, not many articles have ended up with criteria matched to the inclusion principles of this review and thus, only 24 articles were retained after all the iterations. The following figure summarizes the process for selection of studies. 


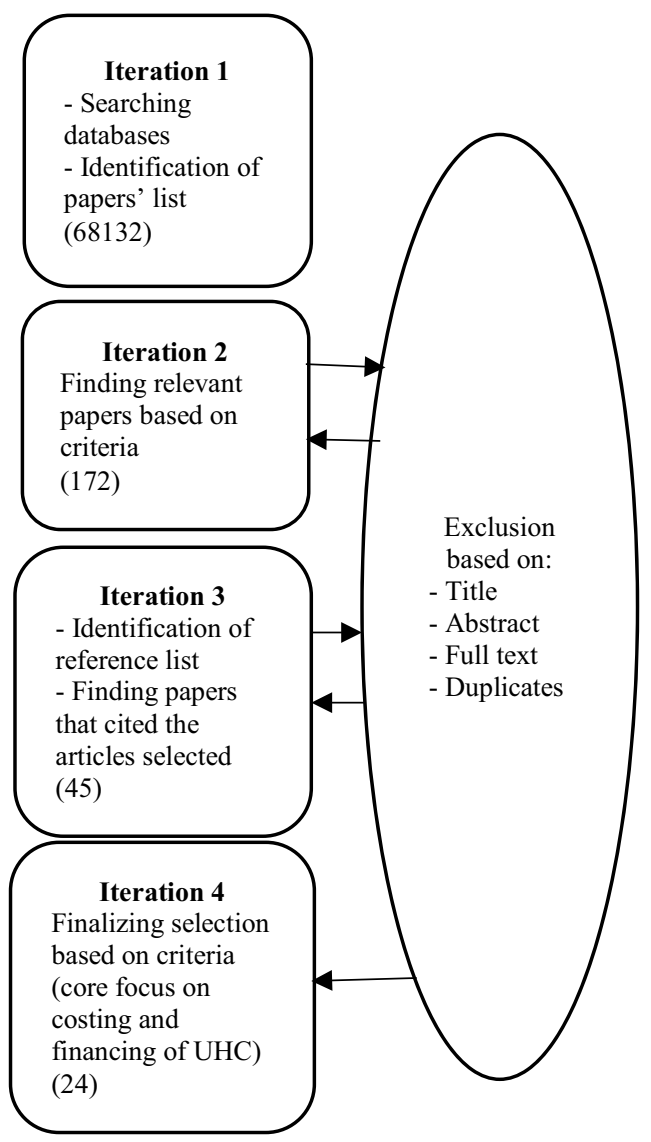

Fig. 6: Selection of studies

The thematic analysis of the selected articles was performed by thorough reviewing of the papers manually. With hand search, some sub-themes were carefully generated which were consolidated to formulate the main themes. The main themes were termed as financing options for healthcare, medical expenses, inequality in healthcare finance, and development of healthcare finance. The following table summarized the main themes and sub-themes with their respective references.
Table 1: Derived key themes from the selected articles

\begin{tabular}{|c|c|c|}
\hline Main themes & Sub-themes & References \\
\hline \multirow{6}{*}{$\begin{array}{l}\text { Financing } \\
\text { options for } \\
\text { healthcare }\end{array}$} & $\begin{array}{l}\text { Out-of-pocket } \\
\text { payment }\end{array}$ & $\begin{array}{l}{[35] ;[36] ;} \\
{[37] ;[38] ;} \\
{[11]}\end{array}$ \\
\hline & Health insurance & [39]; [35] \\
\hline & Tax financing & $\begin{array}{l}{[40] ;[41] ;} \\
{[19] ;[42] ;} \\
{[43]}\end{array}$ \\
\hline & Pooling of funds & {$[35] ;[44]$} \\
\hline & $\begin{array}{c}\text { Pay-for- } \\
\text { performance }\end{array}$ & $\begin{array}{l}{[45] ;[35] ;} \\
{[46] ;[47] ;} \\
{[48] ;[49] ;} \\
{[50]}\end{array}$ \\
\hline & $\begin{array}{l}\text { Compulsory } \\
\text { insurance }\end{array}$ & $\begin{array}{l}{[51] ;[52] ;} \\
{[53] ;}\end{array}$ \\
\hline \multirow{3}{*}{$\begin{array}{l}\text { Medical } \\
\text { expenses }\end{array}$} & Cost constraints & $\begin{array}{l}54] ;[55] ; \\
{[17,56] ;} \\
{[57] ;[58]}\end{array}$ \\
\hline & $\begin{array}{c}\text { Cost } \\
\text { effectiveness }\end{array}$ & $\begin{array}{l}{[59] ;[60] ;} \\
{[61]}\end{array}$ \\
\hline & Health insurance & $\begin{array}{l}\text { [62]; [63]; } \\
{[64] ;[65]}\end{array}$ \\
\hline \multirow{3}{*}{$\begin{array}{l}\text { Inequality in } \\
\text { healthcare } \\
\text { finance }\end{array}$} & $\begin{array}{l}\text { Inequality as } \\
\text { impediment of } \\
\text { UHC }\end{array}$ & {$[66] ;[67]$} \\
\hline & $\begin{array}{l}\text { Disproportionate } \\
\text { cost burdens }\end{array}$ & $\begin{array}{l}{[68] ;[69] ;} \\
{[11] ;[70] ;} \\
{[71]}\end{array}$ \\
\hline & $\begin{array}{c}\text { Discriminatory } \\
\text { healthcare } \\
\text { service } \\
\end{array}$ & $\begin{array}{l}{[72] ;[73] ;} \\
{[57] ;[74] ;} \\
{[63] ;[41]}\end{array}$ \\
\hline \multirow{2}{*}{$\begin{array}{c}\text { Policy } \\
\text { recommendations } \\
\text { for healthcare } \\
\text { finance }\end{array}$} & $\begin{array}{l}\text { Generic policy } \\
\text { recommendations }\end{array}$ & {$[56] ;[67]$} \\
\hline & $\begin{array}{l}\text { Specialized } \\
\text { factors to be } \\
\text { considered }\end{array}$ & $\begin{array}{l}{[61] ;[75] ;} \\
{[76] ;[42]}\end{array}$ \\
\hline
\end{tabular}

\subsection{Data Extraction and Synthesis}

While extracting data from the selected papers, some key themes were extracted and grouped into several categories. The information has been segmented into financing means of universal healthcare, cost effectiveness of medical expenses, tax finance, cross subsidy, separate medical insurance system, inequality at different demographic factors and policy 
recommendations. While most of the studies offered qualitative discussions over the universal healthcare, a number of studies were found to be analyzing field data from respondents on diverse aspects of universal healthcare. Qualitative studies mainly offered insights about the practices of healthcare and presented issues in concurrent health systems from their respective contexts. Quantitative researches adopted different graphical, tabular, and statistical means for interpreting collected field data and concluded with particular study objectives relating to financing of universal healthcare. The following section offers a detailed picture of the characteristics of the selected studies.

\subsection{Characteristics of studies}

An experimental iterative approach was followed in analyzing the data extracted from the selected articles. The guidelines of Law, Stewart, Pollock, Letts, Bosch and Westmorland [77] for a realistic review have been adopted in this regard. Several other studies have also presented the mechanism specified by Law, Stewart, Pollock, Letts, Bosch and Westmorland [77] in their analyses [78]; [79]. The approach of realist review analyses the data for categorizing the reported evidence from a social context, which is used for the universal healthcare financing and presented below.

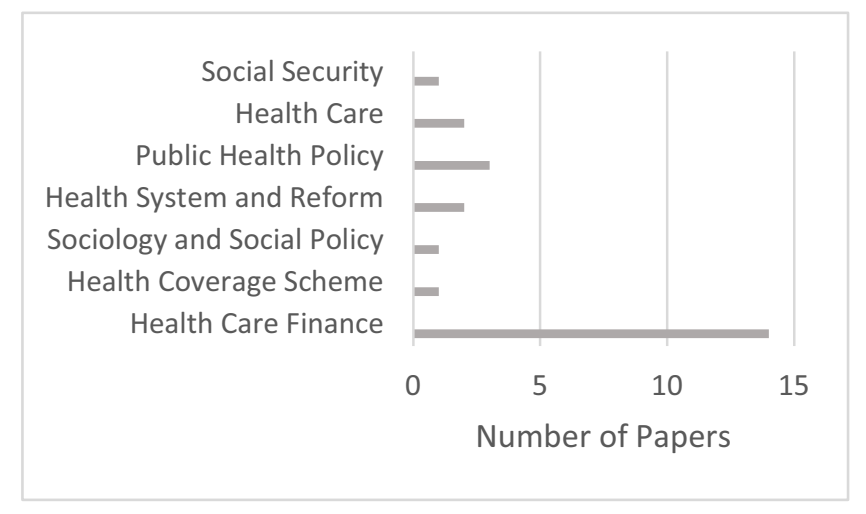

Fig. 7: Different Fields of Publication

Figure 07 presents the distribution of papers with their fields of publications. Healthcare finance has been identified as the most preferred field of publication for the researchers in health finance arena. Among the selected papers, authors of 14 papers have chosen the healthcare finance field for publishing respective papers. Beside healthcare finance, three of the articles have been published in the field of public health policy. Other than these two fields, health coverage scheme, sociology and social policy, health system and reform, public health policy, health care and social security have been on the preferred list for the area of publication by the authors of health finance studies.

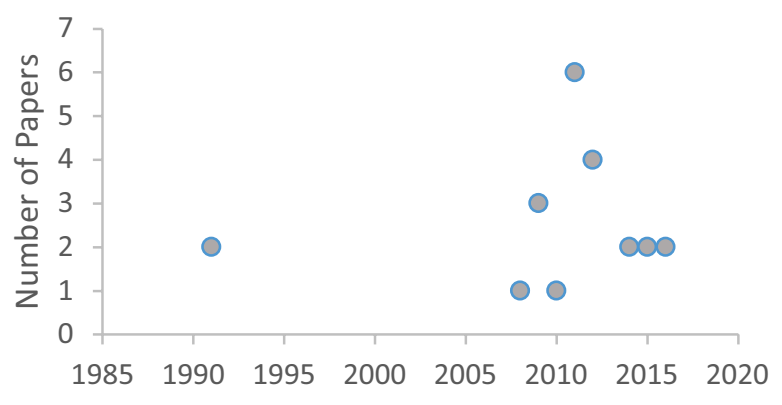

Fig. 8: Publication Years

The distribution of selected articles on health finance was plotted along with the years of publication in figure 08. The trend in the graph clarifies that, after the year 2010, an increasing interest of authors is evident in the areas of health finance. Though yearly fluctuations are prevalent in the number of articles published per year, financing issues of universal healthcare have been successful in capturing much attention from researchers as a crucial concern of health finance. The overall trend is positive and offers optimist forecasting for the years to come.

Table 2: Initial search results from databases

\begin{tabular}{|l|c|}
\hline Name of the database & Initial search results \\
\hline IEEE & 15039 \\
\hline Emerald & 5953 \\
\hline Taylor and Francis & 41,285 \\
\hline ScienceDirect & 1496 \\
\hline JSTOR & 329 \\
\hline Wiley online library & 1493 \\
\hline PubMed & 227 \\
\hline Google Scholar & 2310 \\
\hline
\end{tabular}

This systematic literature review has covered eight online databases namely PubMed, Google Scholar, IEEE, Emerald, Taylor and Francis, ScienceDirect, JSTOR and Wiley online library. The initial results of the database search yielded 68132 articles and after four iterations with specific exclusion criteria, 24 articles were selected for thorough review. Two of the articles were found to be duplicate among the databases. The detailed distribution of the initial search is presented in Table 02 . 
Among the articles, selected finally for review, JSTOR has been found to be the database containing the most relevant articles. The reason behind JSTOR to come first is that the articles found in JSTOR were multidisciplinary and thus, ended up in the database as it has a good collection of journals listed with it. Surprisingly enough, Emerald yielded more relevant articles than PubMed and the reason behind this is that PubMed has included duplicate articles, which were excluded from the analysis. Articles related to financing universal health care has also been published rigorously in Taylor and Francis, Google Scholar, Wiley online library, and IEEE, ranked according to the number of relevant articles found. Surprisingly, no articles from ScienceDirect can be retained after filtering with the exclusion criteria. Figure 09 presented the number of selected articles with their respective databases.

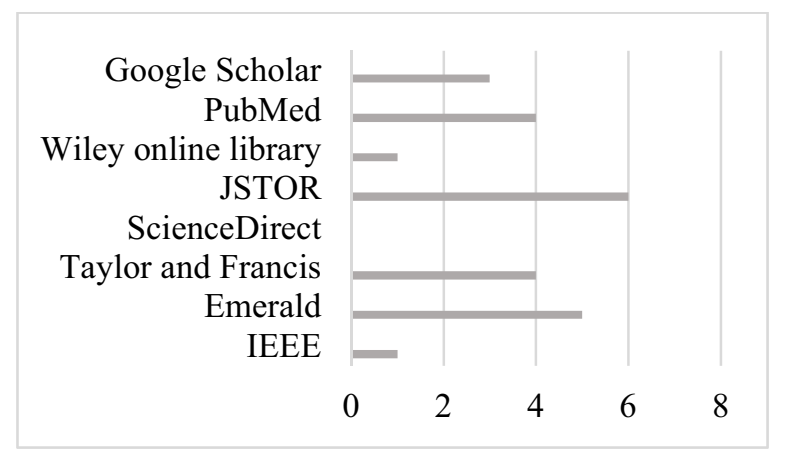

Fig. 9: Selected Articles by Databases

Figure 10 illustrated the research approaches so used in the selected articles for this study. The quantitative research approach was popular among the studies related to universal healthcare finance. As the financial aspects and their analysis require more quantitative data and numerical representation, 18 of the selected articles (75\%) have adopted a quantitative mechanism for realizing the study objectives. However, a qualitative approach was also used in the relevant studies and five articles (21\%) have discussed diverse issues of healthcare finance in a qualitative manner. Only one of the selected articles has adopted a mixed-method mechanism.

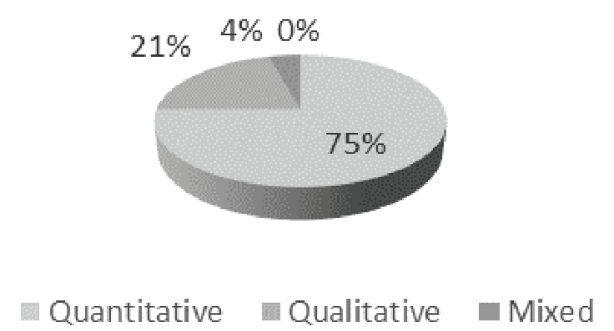

Fig. 10: Research Approach

The geographical distribution of researches has implications in this systematic review as it offers an idea about which areas of the globe are more concerned with universal healthcare and its financing options. Figure 11 shows that most of the studies were conducted in the Asia and Africa as far as the continents are concerned. Europe and North America have been contributing with similar fashion ( $8 \%$ each).

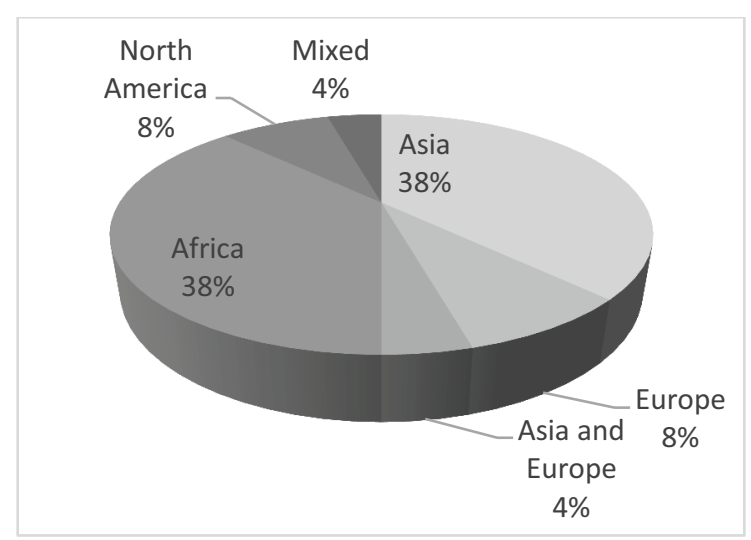

Fig. 11: Geographical Distribution

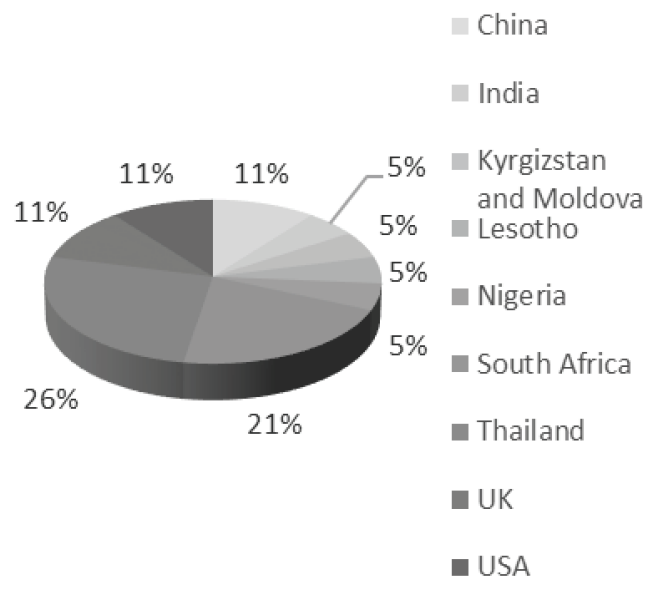

Fig 12: Country wise Distribution 
As per country level statistics, Thailand has attracted much attention of the researchers in universal healthcare financing. Thailand being at the top of the list is no surprise as the country has been considered as the pioneer and successful trendsetter of healthcare finance. Similar to the geographical distribution, South Africa comprises $21 \%$ of the selected studies and is placed next to Thailand in the distribution of studies. China, UK, and the USA have $11 \%$ contribution each in studies of universal healthcare.

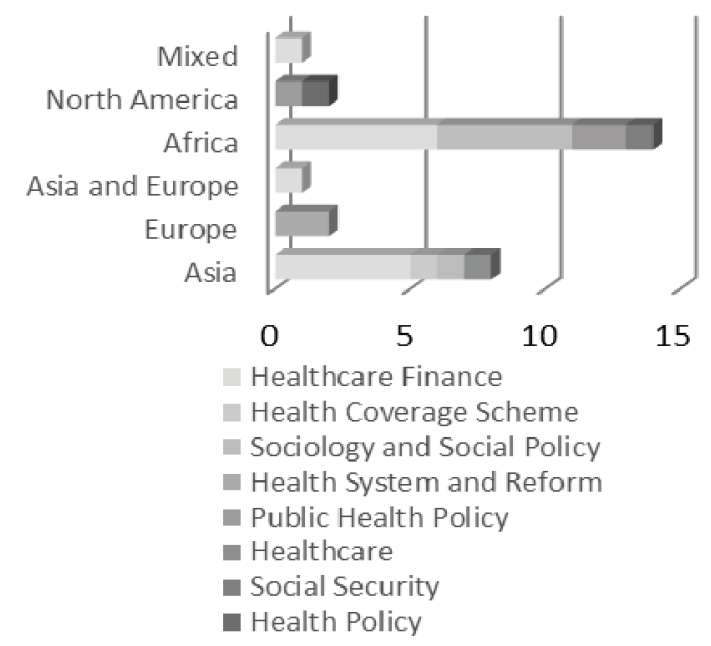

Fig. 13: Fields of Publication by Region

Figure 13 depicts the continent wise fields of publication where Africa is highlighted much as the publications contributed to health finance literature from different arena. Healthcare finance and Sociology \& social policy have been in the preferred fields of publication by researchers. In Asia, the studies contributed more in the healthcare finance, followed by health coverage scheme, sociology and social policy and healthcare.

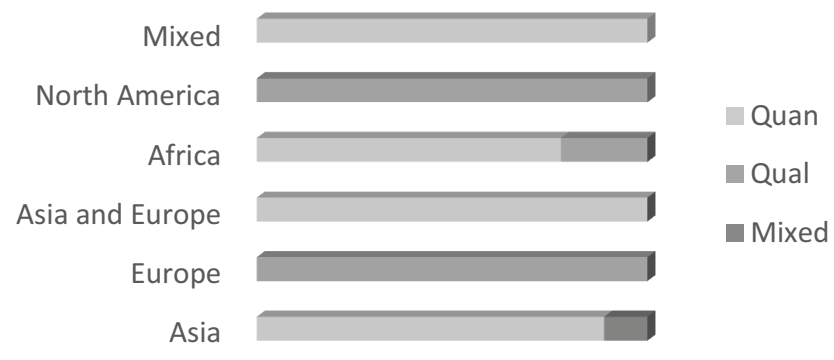

Fig. 14: Research Approaches by Region
In the case of researchers' adoption of research approaches, most of the continents preferred the quantitative approach due to the nature of the study, related to financial matters. Selected articles from North America and Europe adopted the qualitative approach of research. Asia and Africa had some mixed methods and qualitative researches respectively.

\subsection{Discussion}

From a number of sub-themes, found through extensive thematic analysis of articles, four major themes have been created. The following discussion offers a structured documentation of the authors' views under each of the major themes.

\subsubsection{Financing options for healthcare}

\subsubsection{Out-of-pocket payment}

A number of financing means are found around the world where different countries adopted differentiated financing method for healthcare financing. Even though out-ofpocket payment mechanism has been available in quite a notable number of countries, especially the developing ones, it is considered the least desirable method of financing healthcare [35]. Such sort of payment method places the total cost burden on health seeking individuals in the absence of cross-subsidization. For the poor and ultra-poor population, out-of-pocket payment constitutes a significant barrier in availing healthcare [36]; [37]; [38]. Due to the out-of-pocket payments in healthcare, nearly 100 million individuals are being fallen below the poverty line every year [11].

\subsubsection{Health insurance}

On the other hand, a number of countries have introduced mandatory health insurance for financing healthcare. However, such sort of insurance funds is being accumulated only from the contribution of formal sector employees as well as employers [39]. Quite a number of high-income and middle-income African and Latin American countries have adopted mandatory health insurance as the financing option for healthcare. Kenya and Tanzania introduced their own health insurance funds, namely National Hospital Insurance Fund in 1966 and National Health Insurance Scheme in 2001 respectively, where the former collects fund from formal sector employees and the later gathers funds from government workers [35]. Later on, Tanzania initiated collecting funds from private sector employees by another mandatory insurance scheme. 


\subsubsection{Tax finance}

Similar to other public goods, using tax finance as the source of fund for healthcare is a popular and proven model of healthcare finance. To achieve universal health coverage, increasing tax revenue was found instrumental in countries with low tax base [40]. Thailand has set a bright example of successful, equitable, and feasible healthcare financing through tax procedure for most of the population [41]. Tax finance method has also been found sustainable for long term healthcare goals as health service providers are linked through closed-ended payment method and contracting model for ensuring good budget for healthcare [41]. Unlike the insurance mechanism, general tax method has been found as the most progressive source of finance for healthcare as it utilizes the existing resources, expertise and mechanisms of the finance ministry in enforcing and collecting the tax payments [42]. Progressive tax practices along with a propoor tax framework for capital gains and profits might support achieving key global health objectives, unlike the tax burdens of consumption taxes [40]. Evidence in this regard is found from the study of Harris, Nxumalo, Ataguba, Govender, Chersich and Goudge [43] where one-third of the study respondents was keen to offer cross-subsidization for others and half of the study sample preferred a progressive financing mechanism for healthcare services.

\subsubsection{Pooling of funds}

From the viewpoint of reducing fragmentation in fund sources, pooling of funds has been an issue, which has, has a close relation to the collection costs and materializing of the relative advantages of both the health insurance and government tax finance. Reducing fragments in funding sources and directing funds from all possible sources to a centralized and well-managed pool are critical to ensure the goals of universal healthcare [35]. Centralization in funding sources has been found to be associated with equity and improvement in healthcare financing where a strong single purchaser health services might be a critical change agent [44]. Achieving cross-subsidization is only possible with integrated funding pools because managing separate funding scheme for different groups limits the benefits of cross-subsidies and it becomes difficult to merge fragmented pools in later stages [35].

\subsubsection{Pay-for-performance}

Pay-for-performance (P4P) or result-based-financing $(\mathrm{RBF})$ or performance-based-financing $(\mathrm{PBF})$ is one of the newer concepts of health finance which makes the beneficiary pay for the healthcare only when the predetermined performance objectives are achieved [45]. With incentives for better quality health services, especially for child and maternal health, or for curing specific diseases i.e. tuberculosis, P4P was instrumental in achieving Millennium Development Goals (MDG) [35]. However, a little evidence is found to support that $\mathrm{P} 4 \mathrm{P}$ has been successful in achieving improvements in service delivery as well as desired impact [46]; [47]; [48]; [49]. Alternatively, adverse impacts of quality of healthcare services were experienced which includes providing more focus to $\mathrm{P} 4 \mathrm{P}$ services at a cost of detriments in other services and inflating performance indicators with false reporting [47]; [35]. In this instance, purchasing of healthcare services through pooled funds and the way citizens can get access to those services are crucial. Purchasing consideration includes entitlements of health service benefits and payment to service providers [50].

\subsubsection{Compulsory insurance}

Compulsory insurance is one of the popular forms of funding arrangement for universal health coverage where governmental legislation enforces citizens for purchasing insurance. Oftentimes, the government provides the insurance service or a mix of the public and private fund can provide standardized service, i.e. Germany. In Canada, citizens contribute to a single public fund for getting healthcare services. Compulsory insurance created the base for US Patient Protection and Affordable Care Act as well as the healthcare system in Switzerland [51]. In some of the countries, which manage healthcare through a mix of public and private funds, the government fixes up the basic level of coverage [52]. In such cases, the insurance providers cannot deny coverage for any policyholders and thus, pricing and service quality become the prime elements of competition. Namsomboon and Kusakabe [76] suggested two viable financing options for universal health coverage, namely single payer system and compulsory insurance. For ensuring universal healthcare, the government can require citizens to avail insurance and take steps so that insurance firms honor all insurance requests and keep uniform pricing for everyone [53].

\subsubsection{Summary of the major findings}

Even though a considerable extent of development is observed in health finance literature, there have been quite a few issues where researchers are still to shed light. 
As far as the out-of-pocket payments are concerned, no viable option to reduce out-of-pocket payments was found in existing literature from the respective country perspective. In the case of mandatory health insurance, a long-standing dilemma resides into the decision regarding the parties to contribute. It is quite sure that there could have been sources of fund for MHI other than formal employees but the currently the burden is placed on them only in most of the countries. No assessment mechanism or framework has been found to get a clear idea about whether to include everyone or only formal sector staffs in the contribution of funds. Government tax financing has been found successful in financing healthcare services in developed nations or middle-income countries. However, no tax framework has been suggested for ultrapoor and developing countries as the similar taxing procedure would not fit in the economic characteristics of such countries. In the case of pooling funds for universal healthcare, fragmentation of funding sources has been a serious issue. However, studies were intermittent in developing a mechanism for centralized pooling of funds to offer maximum defragmentation. Studies have covered the P4P systems and its diverse aspects fairly well with the concurrent issues associated with it. Nevertheless, no studies have been found instrumental in discussing effective measures to eradicate flaws in P4P systems, including the performance inflation issues and detrimental services other than the P4P ones.

\subsubsection{Medical expenses}

\subsubsection{Medical expense management and issues}

The success of universal health care in Thailand with government subsidization for pro-poor incidence is exemplary in Asia region, which has been followed by Sri Lanka and Malaysia later on [54]. Even though out-ofpocket payments for healthcare service has been contributory to catastrophic health financing, India, Bangladesh, China, Vietnam, Nepal and other developing countries in Asia have adopted out-of-pocket payments in healthcare finance for long since [55]. Xu, Evans, Kawabata, Zeramdini, Klavus and Murray [17] found that out-of-pocket payments were a significant determinant for households with catastrophic expenditure. Song, Feng, Xue and Huang [56] have found that growth rate of healthcare costs is a crucial factor for expenditures in medical insurance. The study results call for strong management of medical service market, reforms in medical organizations to control healthcare costs and standardizing charges for healthcare service (Song et al. 2010). In a study with South Africa, Ghana, and
Tanzania, healthcare financing was found progressive along with direct taxes [57]. Hauck, Thomas and Smith [58] mentioned six constraints of health system design within which implementation costs of such health system was a noteworthy constraint.

\subsubsection{Cost-effectiveness of healthcare finance}

Cost-effectiveness of healthcare finance has been in the central point of several studies. Affordability of health services should be distinguished from cost-effective health technologies [59]. Health technologies can be costeffective but they should be affordable to ensure the end users' financial benefit. China has been successful in tackling the rising healthcare costs in recent years through reforms in provider payment mechanism [60]. Among the measures adopted, case-based and flat unit rate payments were mentionable steps towards achieving cost effectiveness in Chinese healthcare system. The absence of linkage between the healthcare budgets and costeffectiveness of healthcare costs creates issues in the materialization of universal healthcare goals [59]. Though Thailand is considered as one of the successful pioneers in implementing universal healthcare, Mee-Udon [61] found that almost 31 percent of the respondents (rural and poor villagers) never used the scheme even after having the UC card and 22 percent of the UC card users expressed dissatisfaction. A number of opportunity costs played significant roles behind such non-use and dissatisfaction [61].

\subsubsection{Reducing catastrophic health expenditure}

Health insurance has been performing as a remedial measure for reduction of catastrophic health expenditure in households that lives below the poverty line. "Aarogyasri" program was started in 2007 in Andhra Pradesh state (Southern India) to rescue poor households from catastrophic health expenditure. Study results found that "Aarogyasri" program has significant contribution in reducing out-of-pocket costs for both inpatient and outpatient expenditures [62]. Social health insurance has had a profound contribution towards materializing the universal health coverage. Mathauer, Doetinchem, Kirigia and Carrin [63] found that social health insurance could offer universal healthcare in a more financially feasible manner. Social health insurance contributions together with government subsidies can mobilize a sustainable and sufficient level of financial resource which will offer a predefined standard of quality healthcare service and low cost-sharing [63]. However, government hospitals have been found to have discriminatory practices for patients. 
Through data from both inpatient and outpatients for 2003-2005, Hirunrassamee and Ratanawijitrasin [64] confirmed that government hospitals utilized expensive items for the patients who have an insurer to pay on the open-ended or closed-ended basis. On the other hand, insurance coverage has impacts in increasing the demand for treatments. However, extending insurance coverage can substantially raise demand for treatments in unintended groups, which might increase total healthcare costs [65].

\subsubsection{Summary of the major findings}

Out-of-pocket costs have been the major element of catastrophic health expenditure for the majority of lowincome and developing countries. Opportunity costs of different sorts along with other constraints create impediments in the way of affordable and equitable healthcare system. Literature gap has been identified in developing a cost effective financial framework, which is capable of reducing such out-of-pocket costs and other opportunity costs, especially from the low-income and developing country contexts.

\subsubsection{Inequality in healthcare finance}

\subsubsection{Healthcare finance (the rich vs. the poor)}

Inequality and un-uniformed access to healthcare facilities created impediments in the realization of universal healthcare fully. Under universal healthcare, facilities for richer portion of the population are found to be better equipped, more refined, and of improved quality in comparison to services offered to poorer communities [66]. Differences in funding sources for caregivers were the primary reasons behind these distinctions as medical institutions used by rich and poor are not alike due to reachability and socioeconomic factors. More government finance should be assigned for the lower levels of care to reduce inequality in public health services [66]. To enable equitable health financing, a pro-poor shift is essential where less regressive or more progressive health financing mechanism is enabled between two timeperiods [67].

\subsubsection{Disproportionate cost burden}

Study findings of Harris, Goudge, Ataguba, McIntyre, Nxumalo, Jikwana and Chersich [68] suggested that the poorest bears healthcare cost burdens disproportionately in countries such as South Africa, which significantly limits cross-subsidization between wealth and poor or healthy and sick. A significant portion of the groups still pays the service fees who are exempted from such payments by government policy [68]. Such practices severely weaken equity objectives led by exemption policies of the government [69]; [11] and prevent financial protection for vulnerable groups and poor households [70]. The malpractices of the discretionary power of bureaucrats and health service providers in enabling exemptions for the wrong people have also been evident [71].

\subsubsection{Exclusion and discrimination}

Citizens within low-income bracket had experienced exclusion from healthcare coverage and, as a result, noteworthy discrimination in healthcare access [72]. Due to increased hypertension and untreated diabetes, excluded groups had a significantly greater probability of death as compared to individuals with healthcare coverage [73]. Mills, Ataguba, Akazili, Borghi, Garshong, Makawia, Mtei, Harris, Macha and Meheus [57] found that richer portion of the society enjoys elevated benefit distribution of healthcare services whereas the low-income groups experience the most sufferings for sickness burden. Uninsured, when hospitalized, are found to be more likely to die within hospitalization due to lack of specialized services [74]. Mathauer, Doetinchem, Kirigia and Carrin [63] advocate on behalf of the social health insurance scheme as it is capable of providing protection from financial risks and optimizes equity in both access and financing of healthcare services. Geographical barriers are mostly responsible for inaccessible healthcare in most pro-poor regions that accelerates healthcare inequality issues even further. Initiatives should be taken for universal free services towards the regions, which lack access to universal healthcare or primary healthcare due to physical barriers [41].

\subsubsection{Summary of the major findings}

Although social health insurance has been the pioneer in ensuring equitable healthcare financing, discriminations in health service are still evident in research findings. Extensive studies are needed to explore the malpractices happening in healthcare rendering agents, caregivers, and hospitals. Ill-practices of insurance firms, which are instrumental for health service providers to offer discriminatory service, should also be carefully examined.

\subsubsection{Policy recommendations for healthcare finance}

\subsubsection{Successful health finance practices}

The contribution of authors in concurrent literature was sound in the areas of development in healthcare finance. 
Song, Feng, Xue and Huang [56] offered some of the crucial suggestions to improve the financial mechanism for universal healthcare and remove inequality. Among the critical recommendations, increasing the medical payment rates appropriately, lowering the level of debt in the medical insurance fund, introducing rational medical fees for senior citizens, enabling medical reserve funds for elderly will enable a better performing and equitable medical insurance fund [56]. Kakwani index of progressivity and some other indices have been used to characterize the shifts in healthcare financing progressivity in different time periods in South Africa, which offer important roles to play in the development of financing mechanism of universal healthcare [67]. Song, Feng, Xue and Huang [56] also emphasized on the medical reforms with a specific focus on controlling the healthcare costs.

\subsubsection{Cultural and social contexts}

Along with the quality of services and opportunity costs, the cultural and social contexts were suggested to be considered while making policies on healthcare finance [61]. Given the availability of data, the healthcare pricing should at least be differentiated by gender, age, and risk of disease where healthcare fund contribution is mandatory [75]. The characteristics of states, communities, markets, and families are also advocated to be kept under consideration while pricing healthcare services. For enabling marginalized populations to have the benefits of universal healthcare schemes, community support and organizing are two very essential elements [76]. To reduce the burden of out-of-pocket payments, initiatives should be taken for a prepayment scheme, assessment of individual contribution in social health insurance funds while adjusting for minimum wage and increment of the progressive source of health finance, i.e. direct taxation [42].

\subsubsection{Summary of the major findings}

A number of studies, i.e. Ataguba [67], have used indices to characterize the shifts in healthcare financing progressivity in different time-periods. Kakwani index of progressivity was popular in particular in these regards. However, no study has been found to use such frameworks in comparing the progress of healthcare financing between countries. Policy recommendations were found in developing financing system of universal healthcare but studies are yet to test the effectiveness of such recommendations in improving equity in service benefits and healthcare financing. As the health-systems experience dynamism due to differentiated country profile and demands of time, the applicability of the suggestions offered by different authors should be examined for a proper outcome.

\section{Conclusions}

Financing universal healthcare still requires much attention but the systematic review provides evidence of increasing interests of the researchers. A mix of dynamic findings was identified in multifaceted areas of costing and financing healthcare in this systematic review. The findings were segmented into four broad categories to present the research interests and developments so published by researchers in financing field of universal healthcare.

Financing options have been one of the major categories of themes where researchers contributed on various aspects for as many as five differentiated financing mechanisms. Medical expenses and their different dimensions were also the preferred areas for quite a number of researches. Constraints created by healthcare costs for successful utilization of universal healthcare, the effectiveness of healthcare costs in terms of ultimate service benefits and contribution of health insurance in creating an equitable healthcare atmosphere were the core concerns of studies in medical expense field.

From the inception of universal healthcare, inequality has been in the center-point of discussions in healthcare finance related studies. The way inequality in health services creates obstacles in materializing the main objectives of universal healthcare has gained much attention. A noteworthy number of researches were found to be dedicated to disproportionate healthcare cost burdens onto individuals and discriminatory healthcare service between the rich and poor groups of the society. Last but not the least, constructive guidelines for developing financing mechanisms for improved universal healthcare were offered in the selected studies. Authors recommended some essential policy actions for overall development in healthcare financing systems and ensuring equity in health services. Besides, some specialized factors i.e. age, gender, place, and contexts were suggested to be considered while adopting and implementing financing policies for universal healthcare. 


\subsection{Limitations}

This systematic review has included only 8 databases which have limited the search results and the number of articles selected for reviewing purpose. The sophisticated nature of the topic (financing universal healthcare) has also been instrumental in the poor selection of articles, as the area still needs many studies to have a rigorous systematic review with multifarious themes.

\subsection{Future Directions}

From the findings of this systematic review, quite a number of significant literature gap can be identified that need further studies. This systematic review will be instrumental as a starting point of gaining researchers attention in healthcare finance, development of more equitable financing options and offering constructive policy guidelines for ensuring affordable and accessible healthcare for all. Future studies can include multidisciplinary theories for finding the impacts of universal healthcare for people of all walks of life. An enhanced number of databases are recommended in the search process for the systematic reviews conducted onwards over the issues of universal healthcare financing. A rigorous review can also be conducted for finding the status and success of universal healthcare in both developed and developing country setting with a comparative presentation.

\section{References}

1. J. Frenk, 'The global health system: strengthening national health systems as the next step for global progress,' PLoS Med, Vol. 7, no. 1, 2010, pp. e1000089.

2. UNICEF., Progress for children: achieving the MDGs with equity: UNICEF, 2010.

3. WHO, World Health Statistics, 2015.

4. Y. Zhang, J. M. Donohue, J. P. Newhouse, and J. R. Lave, 'The effects of the coverage gap on drug spending: a closer look at Medicare Part D,' Health Affairs, Vol. 28, no. 2, 2009, pp. w317-w325.

5. M. Chopra, A. Sharkey, N. Dalmiya, D. Anthony, and N. Binkin, 'Strategies to improve health coverage and narrow the equity gap in child survival, health, and nutrition,' The Lancet, Vol. 380, no. 9850, 2012, pp. 1331-1340.

6. G. Lagomarsino, A. Garabrant, A. Adyas, R. Muga, and N. Otoo, 'Moving towards universal health coverage: health insurance reforms in nine developing countries in Africa and Asia,' The Lancet, Vol. 380, no. 9845, 2012, pp. 933-943.
7. J.-F. R. Lu, and W. C. Hsiao, 'Does universal health insurance make health care unaffordable? Lessons from Taiwan,' Health affairs, Vol. 22, no. 3, 2003, pp. 77-88.

8. Humanium. "Right to Health around the Globe - Together for Children's Rights," 2 August, 2016; http://www.humanium.org/en/world/right-to-health/.

9. D. B. Evans, J. Hsu, and T. Boerma, 'Universal health coverage and universal access,' Bulletin of the World Health Organization, Vol. 91, no. 8, 2013, pp. 546-546A.

10. W. D. Savedoff, D. de Ferranti, A. L. Smith, and V. Fan, 'Political and economic aspects of the transition to universal health coverage,' The Lancet, Vol. 380, no. 9845, 2012, pp. 924-932.

11. WHO, The World Health Report - Health Systems Financing: The Path to Universal Coverage, Geneva, Switzerland, 2010.

12. K. Shibuya, H. Hashimoto, N. Ikegami, A. Nishi, T. Tanimoto, H. Miyata, K. Takemi, and M. R. Reich, 'Future of Japan's system of good health at low cost with equity: beyond universal coverage,' The Lancet, Vol. 378, no. 9798, 2011, pp. 1265-1273.

13. M. Marmot, S. Friel, R. Bell, T. A. Houweling, S. Taylor, and C. o. S. D. o. Health, 'Closing the gap in a generation: health equity through action on the social determinants of health,' The Lancet, Vol. 372, no. 9650, 2008, pp. 16611669.

14. C. Koopman, K. R. Pelletier, J. F. Murray, C. E. Sharda, M. L. Berger, R. S. Turpin, P. Hackleman, P. Gibson, D. M. Holmes, and T. Bendel, 'Stanford presenteeism scale: health status and employee productivity,' Journal of occupational and environmental medicine, Vol. 44, no. 1, 2002, pp. 14-20.

15. M. Prasad, P. Wahlqvist, R. Shikiar, and Y.-C. T. Shih, 'A review of self-report instruments measuring health-related work productivity,' Pharmacoeconomics, Vol. 22, no. 4, 2004, pp. 225-244.

16. J. H. Lofland, L. Pizzi, and K. D. Frick, 'A review of health-related workplace productivity loss instruments,' Pharmacoeconomics, Vol. 22, no. 3, 2004, pp. 165-184.

17. K. Xu, D. B. Evans, K. Kawabata, R. Zeramdini, J. Klavus, and C. J. Murray, 'Household catastrophic health expenditure: a multicountry analysis,' The lancet, Vol. 362, no. 9378, 2003, pp. 111-117.

18. M. S. Yardim, N. Cilingiroglu, and N. Yardim, 'Catastrophic health expenditure and impoverishment in Turkey,' Health policy, Vol. 94, no. 1, 2010, pp. 26-33.

19. S. Limwattananon, V. Tangcharoensathien, and P. Prakongsai, 'Catastrophic and poverty impacts of health payments: results from national household surveys in Thailand,' Bulletin of the World Health Organization, Vol. 85, no. 8, 2007, pp. 600-606.

20. Y. Li, Q. Wu, L. Xu, D. Legge, Y. Hao, L. Gao, N. Ning, and G. Wan, 'Factors affecting catastrophic health 
expenditure and impoverishment from medical expenses in China: policy implications of universal health insurance,' Bulletin of the World Health Organization, Vol. 90, no. 9, 2012, pp. 664-671.

21. P. Braveman, and S. Gruskin, 'Defining equity in health,' Journal of epidemiology and community health, Vol. 57, no. 4, 2003, pp. 254-258.

22. K. Meades, and R. Roberts, 'Universal health care,' American Heart Hospital Journal, Vol. 5, no. 4, 2007, pp. 217-222.

23. WHO, Health financing mechanisms: private health insurance, Geneva, Switzerland, 2008.

24. D. Stuckler, A. B. Feigl, S. Basu, and M. McKee, "The political economy of universal health coverage."

25. OECD. "OECD Health Statistics," 2 August, 2016; https://www.oecd.org/health/health-systems/FocusHealth-Spending-2015.pdf.

26. J. M. Sutherland, E. S. Fisher, and J. S. Skinner, 'Getting past denial - the high cost of health care in the United States,' New England Journal of Medicine, Vol. 361, no. 13, 2009, pp. 1227-1230.

27. D. W. Bates, S. Saria, L. Ohno-Machado, A. Shah, and G. Escobar, 'Big data in health care: using analytics to identify and manage high-risk and high-cost patients,' Health Affairs, Vol. 33, no. 7, 2014, pp. 1123-1131.

28. L. Wyszewianski, 'Financially catastrophic and high-cost cases: definitions, distinctions, and their implications for policy formulation,' Inquiry, 1986, pp. 382-394.

29. M. Wu, Y. Xin, H. Wang, and W. Yu, 'Private and public cross-subsidization: financing Beijing's health-insurance reform,' Health policy, Vol. 72, no. 1, 2005, pp. 41-52.

30. T. E. Getzen, 'Health care is an individual necessity and a national luxury: applying multilevel decision models to the analysis of health care expenditures,' Journal of health economics, Vol. 19, no. 2, 2000, pp. 259-270.

31. N. Ikegami, and J. C. Campbell, 'Japan's health care system: containing costs and attempting reform,' Health affairs, Vol. 23, no. 3, 2004, pp. 26-36.

32. B. Kitchenham, 'Procedures for performing systematic reviews,' Keele, UK, Keele University, Vol. 33, no. 2004, 2004, pp. 1-26.

33. O. Dieste, A. Grimán, and N. Juristo, 'Developing search strategies for detecting relevant experiments,' Empirical Software Engineering, Vol. 14, no. 5, 2009, pp. 513-539.

34. S. Vichitvanichphong, D. Kerr, A. Talaei-Khoei, and A. Ghapanchi, "Analysis of research in adoption of assistive technologies for aged care." pp. 1-11.

35. D. McIntyre, 'What healthcare financing changes are needed to reach universal coverage in South Africa?,' SAMJ: South African Medical Journal, Vol. 102, no. 6, 2012, pp. 489-490.
36. M. Lagarde, and N. Palmer, 'The impact of user fees on access to health services in low-and middle-income countries,' The Cochrane Library, 2011.

37. M. d. S. Frontières, International Activity Report, 2008.

38. R. Yates, 'Women and children first: an appropriate first step towards universal coverage,' Bulletin of the World Health Organization, Vol. 88, no. 6, 2010, pp. 474-475.

39. G. Carrin, C. James, and W. H. Organization, 'Reaching universal coverage via social health insurance: key design features in the transition period,' 2004.

40. A. Reeves, M. McKee, S. Basu, and D. Stuckler, 'The political economy of austerity and healthcare: Crossnational analysis of expenditure changes in 27 European nations 1995-2011,' Health Policy, Vol. 115, no. 1, 2014, pp. 1-8.

41. P. Prakongsai, S. Limwattananon, and V. Tangcharoensathien, 'The equity impact of the universal coverage policy: lessons from Thailand,' Adv Health Econ Health Serv Res, Vol. 21, 2009, pp. 57-81.

42. S. Limwattananon, V. Vongmongkol, P. Prakongsai, W. Patcharanarumol, K. Hanson, V. Tangcharoensathien, and A. Mills, 'The equity impact of Universal Coverage: health care finance, catastrophic health expenditure, utilization and government subsidies in Thailand,' Consortium for Research on Equitable Health Systems, Ministry of Public Health, http://r4d. dfid. gov. uk/Output/188980, 2011.

43. B. Harris, N. Nxumalo, J. E. Ataguba, V. Govender, M. Chersich, and J. Goudge, 'Social solidarity and civil servants' willingness for financial cross-subsidization in South Africa: Implications for health financing reform,' Journal of public health policy, Vol. 32, no. 1, 2011, pp. S162-S183.

44. J. Kutzin, M. Jakab, and S. Shishkin, 'From scheme to system: social health insurance funds and the transformation of health financing in Kyrgyzstan and Moldova,' Advances in health economics and health services research, Vol. 21, 2009, pp. 291-312.

45. A. Honda, ' 10 best resources on... pay for performance in low-and middle-income countries,' Health policy and planning, Vol. 28, no. 5, 2013, pp. 454-457.

46. C. Eldridge, and N. Palmer, 'Performance-based payment: some reflections on the discourse, evidence and unanswered questions,' Health policy and planning, Vol. 24, no. 3, 2009, pp. 160-166.

47. M. Lagarde, A. Haines, and N. Palmer, 'Conditional cash transfers for improving uptake of health interventions in low-and middle-income countries: a systematic review,' Jama, Vol. 298, no. 16, 2007, pp. 1900-1910.

48. A. D. Oxman, and A. Fretheim, 'Can paying for results help to achieve the Millennium Development Goals? Overview of the effectiveness of results-based financing,' 
Journal of Evidence-Based Medicine, Vol. 2, no. 2, 2009, pp. $70-83$.

49. S. Witter, A. Fretheim, F. L. Kessy, and A. K. Lindahl, 'Paying for performance to improve the delivery of health interventions in low-and middle-income countries,' Cochrane Database Syst Rev, Vol. 2, no. 2, 2012, pp. CD007899.

50. J. Kutzin, 'A descriptive framework for country-level analysis of health care financing arrangements,' Health policy, Vol. 56, no. 3, 2001, pp. 171-204.

51. M. Tomasky, "Healthcare vote: Barack Obama passes US health reform by narrow margin," 2 August, The Guardian, 2010.

52. M. Varkevisser, and S. A. van der Geest, 'Competition among social health insurers: a case study for the Netherlands, Belgium and Germany,' Research in Healthcare Financial Management, Vol. 7, no. 1, 2002, pp. 65-85.

53. M. Rothschild, and J. Stiglitz, "Equilibrium in competitive insurance markets: An essay on the economics of imperfect information," Foundations of Insurance Economics, pp. 355-375: Springer, 1976.

54. O. O'donnell, E. Van Doorslaer, R. P. Rannan-Eliya, A. Somanathan, S. R. Adhikari, B. Akkazieva, D. Harbianto, C. C. Garg, P. Hanvoravongchai, and A. N. Herrin, 'Who pays for health care in Asia?,' Journal of health economics, Vol. 27, no. 2, 2008, pp. 460-475.

55. E. Van Doorslaer, O. O'Donnell, R. P. Rannan-Eliya, A. Somanathan, S. R. Adhikari, C. C. Garg, D. Harbianto, A. N. Herrin, M. N. Huq, and S. Ibragimova, 'Catastrophic payments for health care in Asia,' Health economics, Vol. 16, no. 11, 2007, pp. 1159-1184.

56. S. Song, L. Feng, X. Xue, and M. Huang, "Public debt of medical security system: Is China following in America's footsteps?." pp. 1473-1477.

57. A. Mills, J. E. Ataguba, J. Akazili, J. Borghi, B. Garshong, S. Makawia, G. Mtei, B. Harris, J. Macha, and F. Meheus, 'Equity in financing and use of health care in Ghana, South Africa, and Tanzania: implications for paths to universal coverage,' The Lancet, Vol. 380, no. 9837, 2012, pp. 126-133.

58. K. Hauck, R. Thomas, and P. C. Smith, 'Departures from Cost-Effectiveness Recommendations: The Impact of Health System Constraints on Priority Setting,' Health Systems \& Reform, Vol. 2, no. 1, 2016, pp. 61-70.

59. J. Cairns, 'Using Cost-Effectiveness Evidence to Inform Decisions as to which Health Services to Provide,' Health Systems \& Reform, Vol. 2, no. 1, 2016, pp. 32-38.

60. S. Tang, J. Tao, and H. Bekedam, 'Controlling cost escalation of healthcare: making universal health coverage sustainable in China,' BMC Public Health, Vol. 12, no. 1, 2012, pp. 1.
61. F. Mee-Udon, 'Universal Health Coverage Scheme impact on well-being in rural Thailand,' International journal of health care quality assurance, Vol. 27, no. 6, 2014, pp. 456-467.

62. V. Y. Fan, A. Karan, and A. Mahal, 'State health insurance and out-of-pocket health expenditures in Andhra Pradesh, India,' International journal of health care finance and economics, Vol. 12, no. 3, 2012, pp. 189-215.

63. I. Mathauer, O. Doetinchem, J. Kirigia, and G. Carrin, 'Reaching universal coverage by means of social health insurance in Lesotho? Results and implications from a financial feasibility assessment,' International Social Security Review, Vol. 64, no. 2, 2011, pp. 45-63.

64. S. Hirunrassamee, and S. Ratanawijitrasin, 'Does your health care depend on how your insurer pays providers? Variation in utilization and outcomes in Thailand,' International journal of health care finance and economics, Vol. 9, no. 2, 2009, pp. 153-168.

65. S. H. Zuvekas, 'Health insurance, health reform, and outpatient mental health treatment: Who benefits?', Inquiry, 1999, pp. 127-146.

66. S. Shamu, J. January, and S. Rusakaniko, 'Who benefits from public health financing in Zimbabwe? Towards universal health coverage,' Global public health, 2015, pp. $1-14$.

67. J. E. Ataguba, 'Assessing equitable health financing for universal health coverage: a case study of South Africa,' Applied Economics, Vol. 48, no. 35, 2016, pp. 3293-3306.

68. B. Harris, J. Goudge, J. E. Ataguba, D. McIntyre, N. Nxumalo, S. Jikwana, and M. Chersich, 'Inequities in access to health care in South Africa,' Journal of public health policy, Vol. 32, no. 1, 2011, pp. S102-S123.

69. D. McIntyre, and L. Gilson, 'Redressing dis-advantage: promoting vertical equity within South Africa,' Health Care Analysis, Vol. 8, no. 3, 2000, pp. 235-258.

70. D. Balabanova, and M. McKee, 'Reforming health care financing in Bulgaria: the population perspective,' Social Science \& Medicine, Vol. 58, no. 4, 2004, pp. 753-765.

71. S. Kikuzawa, S. Olafsdottir, and B. A. Pescosolido, 'Similar pressures, different contexts: Public attitudes toward government intervention for health care in 21 nations,' Journal of Health and Social Behavior, Vol. 49, no. 4, 2008, pp. 385-399.

72. N. Lurie, N. B. Ward, M. F. Shapiro, and R. H. Brook, 'Termination from Medi-Cal-does it affect health?,' New England Journal of Medicine, Vol. 311, no. 7, 1984, pp. 480-484.

73. K. Davis, 'Inequality and access to health care,' The Milbank Quarterly, 1991, pp. 253-273.

74. J. Hadley, E. P. Steinberg, and J. Feder, 'Comparison of uninsured and privately insured hospital patients: condition on admission, resource use, and outcome,' Jama, Vol. 265, no. 3, 1991, pp. 374-379. 
75. H. McLeod, and P. Grobler, 'The role of risk equalization in moving from voluntary private health insurance to mandatory coverage: the experience in South Africa,' Advances in health economics and health services research, Vol. 21, 2008, pp. 159-196.

76. B. Namsomboon, and K. Kusakabe, 'Social protection for women homeworkers: a case of healthcare services in Thailand,' International Journal of Sociology and Social Policy, Vol. 31, no. 1/2, 2011, pp. 123-136.

77. M. Law, D. Stewart, N. Pollock, L. Letts, J. Bosch, and M. Westmorland, 'Critical review form-quantitative studies,' McMaster University: Occupational Therapy EvidenceBased Practice Research Group, 1998.
78. A. Talaei-Khoei, P. Ray, N. Parameshwaran, and L. Lewis, 'A framework for awareness maintenance,' Journal of Network and Computer applications, Vol. 35, no. 1, 2012, pp. 199-210.

79. A. Bakshi, A. Talaei-Khoei, and P. Ray, 'Adaptive policy framework: A systematic review,' Journal of Network and Computer Applications, Vol. 36, no. 4, 2013, pp. 12611271. 